\title{
MORALIZAÇÃO DA ADMINISTRAÇÃO PÚBLICA: CHEGOU A VEZ DOS TRIBUNAIS DE CONTAS
}

Coluna publicada em 4.4.2017: <https://www.conjur.com.br/2017-abr-04/ contas-vista-moralizacao-administracao-publica-vez-tribunais-contas $>$

Em 29 de março de 2017 o país foi surpreendido por mais uma operação da Polícia Federal, "O Quinto do Ouro", que, de forma inédita, prendeu nada menos do que cinco Conselheiros e um ex-Conselheiro Tribunal de Contas do Estado do Rio de Janeiro, produzindo um novo capítulo que mancha a história da nossa administração pública e diretamente ligada ao Direito Financeiro. Um fato que poderá até mesmo inviabilizar a continuidade das atividades do órgão. $\mathrm{O}$ fato foi amplamente noticiado por todos os órgãos de imprensa, levando mais uma vez a sociedade brasileira a indignar-se com os ocupantes de altos cargos na administração pública.

Uma oportunidade que não pode ser perdida para trazer à discussão um tema que há tempos vem sendo objeto de debate, e agora se torna um momento propício para intensificar as discussões a respeito: a forma de composição dos Tribunais de Contas.

Deixarei de ressaltar a importância que os Tribunais de Contas sempre tiveram e que aumenta a cada dia, pois já o fiz em outras oportunidades, ${ }^{1}$ como se pode constatar da história recente de nosso país, em que tiveram relevante participação na constatação e investigação de má administração das finanças públicas, que no âmbito federal levaram ao impeachment da Presidente da República.

\footnotetext{
Coluna Tribunais de Contas são os guardiōes do dinheiro público, publicada em 14 de janeiro de 2014; e coluna "PEC do padrão mínimo" vai aperfeiçoar Tribunais de Contas, publicada em 26 de julho de 2016. Ambas constam deste livro.
} 
Para a continuidade e aperfeiçoamento desta importante função e bem cumprirem suas finalidades constitucionais, é imprescindível que seus quadros sejam compostos por servidores da mais alta qualificação e que possam agir com imparcialidade, especialmente em face de seu objeto de atuação, que no mais das vezes envolvem altas somas de recursos públicos.

Mas, afinal, quem são os Ministros ou Conselheiros dos Tribunais de Contas?

A Constituição trata do tema no art. 73 , que estabelece os requisitos para o preenchimento do cargo de Ministro do Tribunal de Contas da União, o que é aplicado por simetria a Estados, Distrito Federal e Municípios, ${ }^{2}$ e são os seguintes:

a) ser brasileiro;

b) ter mais de trinta e cinco e menos de sessenta e cinco anos de idade;

c) idoneidade moral e reputação ilibada;

d) notórios conhecimentos jurídicos, contábeis, econômicos e financeiros ou de administração pública;

e) mais de dez anos de exercício de função ou de efetiva atividade profissional que exija os conhecimentos jurídicos, contábeis, econômicos e financeiros ou de administração pública.

Houve uma considerável evolução da Constituição de 1988 em comparação com a Carta de 1967, na qual, como lembra Mileski, os membros dos Tribunais de Contas eram indicados apenas pelo Chefe do Poder Executivo, por ele nomeados após aprovação do Congresso. Atualmente, há nomeações repartidas entre governo e parlamento. ${ }^{3}$

Preenchidos esses requisitos, a escolha é feita pelo Chefe do Poder Executivo e pelo Poder Legislativo do ente da federação respectivo. No âmbito da União, o Presidente da República indica 3 dos 9 membros, sendo dois alternadamente dentre Auditores e membros do Ministério Público junto ao Tribunal, carreiras providas por concursos públicos, indicados em lista tríplice pelo Tribunal, segundo os

2 O preceito veiculado pelo art. 73 da Constituição do Brasil aplica-se, no que couber, à organização, à composição e à fiscalização dos Tribunais de Contas dos Estados e do Distrito Federal, bem como dos tribunais e conselhos de contas dos Municípios. Imposição do modelo federal nos termos do art. 75. A inércia da Assembleia Legislativa cearense relativamente à criação de cargos e carreiras do Ministério Público especial e de auditores que devam atuar junto ao tribunal de contas estadual consubstancia omissão inconstitucional (ADI 3.276, rel. Min. Eros Grau, j. 2.6.2005. E ainda: ADI 374, rel. Min. Dias Toffoli, j. 22.3.2012).

3 O controle da gestão pública. São Paulo: RT, 2003, p. 216. 
critérios de antiguidade e merecimento. A indicação deve ser aprovada pelo Senado. As outras vagas ficam a cargo do Congresso Nacional.

Nos Estados, a distribuição em terços das indicaçôes do Executivo e do Legislativo encontra alguma dificuldade, em razão de haver nestas unidades 7 membros dos Tribunais de Contas, e não 9. No âmbito regional, esta questão foi resolvida por decisão do Supremo Tribunal Federal, segundo a qual, para manter a simetria com o plano federal, a divisão de vagas seria de 3 para o Chefe do Executivo e 4 para o Legislativo, permitindo-se, assim, que os Governadores escolham, alternadamente, entre Auditores, membros do Ministério Público e uma indicação de livre nomeação. ${ }^{4}$ Ressalte-se que os Municípios de São Paulo (com 5 Conselheiros) e Rio de Janeiro são os únicos que têm Tribunais de Contas Municipais.

Se os requisitos exigidos preveem pessoas de alta qualificação pessoal e profissional, fica a pergunta: por que ocorrem fatos como o da semana passada, em que vários dos integrantes de um dos mais importantes Tribunais de Contas do país chegam ao ponto de serem presos, com fortes indícios de terem participado de atos criminosos?

Ver-se-á que muitos fatores podem, ao menos em parte, explicar esse fenômeno.

No que se refere aos requisitos, aqueles que têm caráter mais objetivo são difíceis de não serem observados. Por outro lado, são menos relevantes sob o ponto de vista da conduta que se espera dos indicados. ${ }^{5}$

O primeiro dos requisitos exige que seja escolhido um cidadão brasileiro. Nesse caso, pode-se entender como sendo a exigência de nacionalidade brasileira, ou seja, admitem-se os brasileiros natos e os naturalizados no pleno exercício de seus direitos políticos, e não apenas os brasileiros natos, haja vista que o cargo em questão não está entre aqueles privativos dos brasileiros natos, nos termos em que dispõe o art. $12, \$ 3^{\circ}$, da Constituição.

O segundo requisito são as idades mínima e máxima. Exige que o Ministro tenha ao menos 35 anos, ou seja, deverá ter completado 35 anos até a data da posse,

4 "É realmente pacífica a jurisprudência do Supremo Tribunal Federal, no sentido de que, nos Tribunais de Contas, compostos por sete membros, três devem ser nomeados pelo Governador (um dentre membros do Ministério Público, um dentre Auditores, e um de livre escolha) e quatro pela Assembleia Legislativa. Só assim se pode conciliar o disposto nos artigos 73, $\$ 2^{\circ}$, incisos I e II, e 75 da Constituição Federal” (STF, ADI-MC 2409/ES, rel. Min. Sydney Sanches).

5 Já tive oportunidade de analisar os requisitos para o preenchimento do cargo de Ministro do TCU em Direito Financeiro na Constituição de 1988 (São Paulo: Oliveira, Mendes, 1998), razão pela qual por vezes farei uso de alguns trechos da referida obra. 
e não poderá ainda ter completado 65 anos. Neste último item, é oportuno ressaltar que o Ministro poderá exercer o cargo com idade superior a 65 anos, haja vista que a aposentadoria compulsória dá-se atualmente aos 75 anos de idade; o que não se permite é assumir o cargo já tendo completado esta idade.

Um pouco mais complexas são as vedações que têm maior grau de subjetividade, abrindo margem a uma discricionariedade na interpretação. É o caso, por exemplo, da exigência que o candidato ao cargo tenha "idoneidade moral e reputação ilibada". Apesar de ser difícil estabelecer critérios que permitam aferir com precisão sua observância (até mesmo porque seu conteúdo pode se alterar com o correr do tempo), alguns parâmetros podem ser observados. Assim, como já escrevemos em outra oportunidade, "uma condenação criminal definitiva é indício forte e seguro que pesa contra o preenchimento deste requisito. Mesmo assim, não se pode considerar esta circunstância de forma absolutamente isolada de um contexto. Uma condenação definitiva por crime de lesão corporal culposa, por exemplo, não pode, por si só, inabilitar alguém para integrar os quadros do Tribunal de Contas, devendo ser feita uma análise mais acurada das circunstâncias que envolvem o caso concreto. Portanto, devem ser levadas em consideração todas as informações acerca da conduta da pessoa durante sua vida para, após uma análise ampla, verificar se há fatos que permitam concluir ser moralmente inidônea e de má reputação. Entre os fatos a serem levados em consideração podemos citar os seguintes: existência de processos judiciais de natureza cível ou criminal; existência de processos administrativos em sua vida funcional, caso tenha exercido cargo ou função pública; títulos protestados; informações negativas em estabelecimentos bancários e órgãos comerciais etc." ${ }^{6}$

6 CONTI, José Mauricio. Direito Financeiro na Constituição de 1988, p. 44. Levantamento da jurisprudência permite encontrar alguns parâmetros, como "envolvimento em fato capitulado como crime de sequestro e extorsão em imputação formal e séria, tendo sido recebida a denúncia contra ele oferecida" (RT 576/55). A conduta do candidato "estar sendo objeto de investigação em processo administrativo, que lhe infringiu uma penalidade" já obstou a nomeação para cargos estatutários em instituições financeiras (TRF-5, Ap. 19236-68.2012.4.05.8300, rel. Des. Fed. José Maria Lucena, j. 27.3.2014). A Delegacia Geral de Polícia de São Paulo, ao regulamentar a concessão de porte de arma aos cidadãos, editou Portaria trazendo critérios bastante objetivos para o fim de apurar a idoneidade do requerente: "comprovação de idoneidade, com apresentação de Certidões de Antecedentes Criminais da Justiça Federal, Estadual, Militar e Eleitoral e de não estar respondendo a inquérito policial ou a processo criminal por infraçôes penais praticadas com violência, grave ameaça ou contra a incolumidade pública" (Portaria 24, de 16.9.97, da Delegacia Geral de Polícia de São Paulo, art. 9º, II). E o Estatuto da OAB também traz dispositivo neste sentido: "Não atende ao requisito de idoneidade moral aquele que 
Não obstante algumas dificuldades em precisar esses conceitos, é injustificável o abrandamento dos requisitos para a nomeação, tendo em vista que os membros dos Tribunais de Contas contam com prerrogativas equivalentes a dos membros do Poder Judiciário (do STJ, no caso de ministros do TCU, e dos Desembargadores, no caso de conselheiros dos tribunais estaduais). Até para que se analisem as circunstâncias de eventual condenação criminal ou por improbidade é que se torna necessário conferir transparência às informações sobre a conduta do indicado.

A respeito do requisito de notórios conhecimentos jurídicos, contábeis, econômicos e financeiros ou de administração pública (previstos no art. $73, \S 1$, III, da Constituição), é fundamental e imprescindível que o indicado apresente um sólido conjunto de conhecimentos relacionados à atividade de controle externo. Este é o propósito constitucional. Não é, igualmente, necessário que a qualificação se apresente em todas as áreas mencionadas em conjunto, mas que em ao menos alguma delas o indicado se destaque. Como, no entanto, tornar menos discricionária a nomeação com base nestes critérios tão amplos, a ser feita ou pelo Poder Legislativo ou pelo Poder Executivo? Ainda que não se possa dar resposta definitiva, oferece informaçôes relevantes a este respeito a diplomação em curso superior referente a alguma das áreas constitucionalmente destacadas, ${ }^{7}$ um conjunto considerável de publicações especializadas e outras atividades que possam recomendar o candidato mesmo que apresente, eventualmente, área de formação distinta da jurídica, econômica, contábil ou administrativa. Não é possível, no entanto, como já mencionado, considerar como pré-requisitos a serem obrigatoriamente preenchidos. Pode ocorrer - e não faltarão exemplos - de engenheiros, médicos e outros profissionais terem longa carreira política, e ocuparem cargos de prefeito, deputado, governador, senador, presidente, o que faz com que, ao longo do tempo, adquiram notórios conhecimentos de administração pública, superiores àqueles obtidos pelos que obtêm graduação em um curso superior nesta área.

tiver sido condenado por crime infamante, salvo reabilitação judicial" (Lei 8.906/1994, art. 8º, $\left.\$ 4^{\circ}\right)$. Outros exemplos podem ser encontrados, como já exposto na mencionada obra.

7 Este requisito, no entanto, foi bastante abrandado pelo Supremo Tribunal Federal, que admite o preenchimento do cargo por candidato que sequer tenha diploma de nível superior, conferindo ampla liberdade para a nomeação: "A qualificação profissional formal não é requisito à nomeação de conselheiro de tribunal de contas estadual. O requisito notório saber é pressuposto subjetivo a ser analisado pelo governador do Estado, a seu juízo discricionário (AO 476, rel. p/ o ac. Min. Nelson Jobim, j. 16.10.1997, DJ de 5.11.1999). 
Por fim, exige a Constituição, além dos notórios conhecimentos em pelo menos uma das áreas a que se refere o artigo $73, \$ 1^{\circ}$, III, contar o postulante ao cargo com mais de 10 anos de exercício de função ou de efetiva atividade profissional que exija os conhecimentos mencionados.

Evidentemente, deve ter este tempo de experiência em pelo menos uma das áreas, não em todas. Também é coerente admitir que seja possível somar tempos de exercício de função em áreas diversas, dentre aquelas cujo conhecimento é exigido. Assim, se o postulante ao cargo exerceu por 5 anos função que exija conhecimentos jurídicos, e por outros 5 anos atividade profissional na área de administração pública, o requisito foi preenchido.

É importante ressaltar ainda que o texto constitucional fala em "efetivo exercício", ou seja, considera imprescindível que a pessoa tenha, de fato e comprovadamente, realizado aquelas atividades durante o período referido. Assim, um bacharel em Direito que esteja inscrito na Ordem dos Advogados por 10 ou mais anos, mas que durante este período não praticou qualquer atividade profissional na área jurídica, não está apto a assumir o cargo de Ministro do Tribunal de Contas.

A realidade nos mostra, contudo, que este rigor na escolha dos Ministros e Conselheiros dos Tribunais de Contas é apenas aparente. Uma injustificável leniência dos responsáveis pela escolha tem sido a regra em boa parte dos Tribunais de Contas do país, deixando transparecer que os critérios políticos são os que prevalecem.

E não há como fazer severas críticas aos critérios e requisitos estabelecidos, uma vez que em outros órgãos, como o Supremo Tribunal Federal, por exemplo, os critérios são ainda mais abertos e flexíveis, e mesmo assim a influência política, no mais das vezes, não tem impedido que os escolhidos atendam as exigências constitucionais.

Lamentavelmente está-se diante de um verdadeiro "costume" que se solidificou entre nossos políticos, que veem os cargos de cúpula dos Tribunais de Contas como integrantes das "cotas" de que dispõem para suas nomeações "apadrinhadas", e agora não se consegue mais desconstruir essa má conduta que se impregnou em nossa administração pública e tem sido a principal responsável pela ocupação indevida desses cargos por candidatos que não preenchem os requisitos constitucionais. É seguramente o que explica a existência de escândalos como o que ocorreu alguns dias atrás, maculando a imagem desses órgãos fundamentais para zelar pela lisura no trato dos recursos públicos. Uma pena, pois os Tribunais de Contas têm e sempre tiveram grandes nomes que muito enobrecem o serviço público, e como sempre alguns acabam praticando atos que prejudicam a imagem de toda a instituição. 
No excelente trabalho produzido recentemente por Juliana Sakai e Natália Paiva ${ }^{8}$ ficou clara essa preponderância dos critérios políticos na nomeação dos Conselheiros dos Tribunais de Contas dos Estados.

Em minucioso levantamento, chegam à conclusão de que os Tribunais de Contas têm seus órgãos de cúpula ocupados majoritariamente por ex-políticos de carreira. O levantamento realizado demonstra ainda que " $80 \%$ ocuparam, antes de sua nomeação, cargos eletivos ou de destaque na alta administração pública (como dirigente de autarquia ou secretário estadual, por exemplo); $23 \%$ sofrem processos ou receberam punição na Justiça ou nos próprios Tribunais de Contas; e 31\% são parentes de outros políticos - em alguns casos, foram nomeados pelos próprios tios, primos ou irmãos governadores". E trazem informações que colocam por terra os requisitos de notórios conhecimentos nas áreas finalísticas específicas da atuação dos Tribunais de Contas: "O conselheiro Antônio Cristóvão Correia de Messias, do TCE-AC, por exemplo, atuou como médico até sua nomeação pelo então governador do estado Orleir Messias Cameli (PPR), seu primo. A conselheira do TCE-GO Carla Cíntia Santillo, filha do ex-governador do estado e ex-conselheiro do TCE-GO Henrique Antônio Santillo, é formada em odontologia e foi deputada por quatro anos antes da nomeação. No TCM-BA, os conselheiros Fernando Vita e Paolo Marconi são jornalistas, tendo trabalhado em veículos de comunicação e assessorias de imprensa. Vita também é escritor de romances".

Encontram-se em tramitação no Congresso Nacional propostas para tornar o processo de indicação de ministros do TCU mais objetivo e menos propenso a favorecer indicações sem respaldo técnico para o exercício do cargo. De acordo com o Projeto de Decreto Legislativo 1.580/2014, os requisitos constitucionais gerais de nomeação (a serem observados tanto nas indicações do Legislativo como do Executivo) receberiam parâmetros adicionais de aferição, tais como a comprovação de cursos de graduação ou pós-graduação em áreas que permitam verificar os notórios conhecimentos jurídicos, contábeis, econômicos, financeiros ou de administração pública. Adicionalmente, as vagas previstas para o Congresso Nacional (dois terços dos nove ministros). Assim, a proposta estabelece que ao menos dois dos seis ministros indicados pelo Poder Legislativo federal sejam auditores, concursados especificamente para o exercício de atividades típicas de controle externo, conforme recomendação da Associação Nacional dos Auditores de Controle Externo dos Tri-

8 Quem são os conselheiros dos Tribunais de Contas? Transparência Brasil. Disponível em: $<$ www.transparencia.org.br $>$.

9 Quem são os conselheiros dos Tribunais de Contas?, cit., p. 8. 
bunais de Contas do Brasil (ANTC). Para evitar potenciais conflitos de interesses entre a conduta como ministro e a vida profissional e política pregressa, veda-se, ainda, que o candidato ao cargo vitalício de Ministro do TCU tenha sido Ministro de Estado ou ocupado cargo equivalente, assim como presidente de entidade da Administração Indireta federal, ou que tenha ainda exercido cargo de representante sindical ou associativo nos três anos anteriores à indicação. ${ }^{10}$

O Estado brasileiro passa por um período de reconstrução, e, para isso, moralizar a ocupação dos altos cargos na administração pública é requisito fundamental. Os Tribunais de Contas, como não se pode deixar de reconhecer, desempenham o papel mais importante na fiscalização da atividade financeira do setor público, tendo um papel central nessa missão de colaborar para esse novo país que está por vir. É preciso também fiscalizar os fiscais.

10 Ver, a propósito, as alterações dos artigos 1º, 2o e $3^{\circ}$ do Decreto Legislativo 6/1993 contidas no Projeto de Decreto Legislativo 1.580/2014. As propostas de emendas constitucionais (PEC) 329/2013 e 40/2016 também trazem importantes contribuiçōes para aperfeiçoar a forma de composição dos Tribunais de Contas. 